\title{
Kaiser, Brittany (2020), La dictadura de los datos
}

\section{David López Jiménez}

\section{(2) OpenEdition}

\section{Journals}

\section{Edición electrónica}

URL: http://journals.openedition.org/rccs/10852

DOI: $10.4000 /$ rccs. 10852

ISSN: 2182-7435

\section{Editor}

Centro de Estudos Sociais da Universidade de Coimbra

\section{Edición impresa}

Fecha de publicación: 1 septiembre 2020

Paginación: 183-185

ISSN: 0254-1106

\section{Referencia electrónica}

David López Jiménez, «Kaiser, Brittany (2020), La dictadura de los datos 》, Revista Crítica de Ciências Sociais [En línea], 122 | 2020, Publicado el 10 septiembre 2020, consultado el 23 septiembre 2020 URL : http://journals.openedition.org/rccs/10852 ; DOI : https://doi.org/10.4000/rccs.10852 


\section{RECENSÕES}

\section{Kaiser, Brittany (2020), La dictadura de los datos. Madrid: HarperCollins, 494 pp. Traducción de Carlos Ramos Malavé}

En la presente monografía se aborda un asunto relativamente conocido gracias al extraordinario documental de Netflix sobre Cambridge Analytica (en adelante CA): El gran hackeo. CA utilizó, sin consentimiento alguno, datos personales de la red social Facebook con el objetivo de dirigirse a determinadas personas, manipularlas y condicionar el sentido de sus votaciones.

Esta empresa británica, en torno a la cual gira la presente monografía, poseía entre 2000 y 5000 datos de cada norteamericano mayor de edad. Esta cifra no pasa desapercibida, pues en virtud de la misma se establecían perfiles. A cada individuo se le atribuía puntuaciones denominadas OCEAN con las que se valoraba su personalidad. Las letras que constituyen el vocablo OCEAN tienen el siguiente significado: $\mathrm{O}$ se refiere a abierto (open); $\mathrm{C}$ es concienzudo; E, extrovertido; A, afable, y $\mathrm{N}$ atañe a neurótico. Según los valores de cada una de esas categorías se decidían los mensajes que podían influir en su conducta. Este planteamiento está relacionado con una aplicación diseñada por Aleksandr Kogan, académico de la Universidad de Cambridge. Aparentemente con una finalidad de investigación académica, diseñó la aplicación This is your digital life que ofrecía un perfil de personalidad, una vez que el usuario hubiera incluido determinados datos. Esa base de datos fue vendida a CA.

Los usuarios recibían mensajes mediante los cuales se determinaba su comportamiento hacia ciertos mandatarios.
CA recurría a Facebook para recabar una gran variedad y tipología de datos. Detrás de cuanto se ha podido determinar subyace la práctica de que se estaba recopilando y monitorizando nuestra información; o sea, lo que algunos han dado en llamar "capitalismo de vigilancia”. En lugar de enfocarse en los consumidores y usuarios, CA puso su atención en los votantes. Da la impresión de que, en sí mismo, el propio modelo de vigilancia de la Red atenta contra los derechos humanos.

Ahora bien, no sólo se recopilaban datos de usuarios, sin su preceptivo consentimiento, sino que los mismos eran objeto de tratamiento en virtud de complejos análisis para trazar perfiles, como ya se adelantó. Dado que cada persona se insertaba en un determinado perfil, se arbitraban los mecanismos oportunos con el objetivo de condicionar su comportamiento. Para manipular las decisiones de los usuarios, un importante porcentaje de empresas recurren a vulnerabilidades psicológicas para influir en sus emociones. Se trata de recurrir a la ingeniería social con el fin de dirigir anuncios o mensajes que incidan en las creencias y determinen el comportamiento en un sentido. Este tipo de modelos puede fomentar la discriminación, ya que segrega a los sujetos en función de su raza, sexo, etnia, religión u opiniones políticas. Brittany Kaiser, autora de la obra, nació en Houston (Texas) y vivió gran parte de su vida en Chicago (Illinois). Es una consultora política estadounidense que pasó del idealismo progresista a posicionarse en lo que podríamos calificar de lado oscuro, 
sin ser consciente en muchos casos; asimismo, inicialmente fue una activa colaboradora en la campaña de Barack Obama. La empresa desde la que Kaiser condicionó el desenlace de importantes acontecimientos mundiales, como el Brexit o las elecciones norteamericanas que dieron la victoria a Donald Trump, modificó la minería de datos y también el análisis de los mismos respecto a las comunicaciones estratégicas de índole electoral. Las actuaciones de CA relacionaban la psicología del comportamiento con la investigación de carácter cuantitativo, ofreciendo una imagen detallada del consumidor y, además, de la competencia y de las tendencias de futuro. La obra consta de un total de veinte apartados. El primer capítulo trata sobre los orígenes de la incorporación laboral de la autora en CA, que se produce como resultado de una comida informal con diversos amigos y colaboradores de la empresa británica. Los capítulos segundo y tercero versan sobre algunos de los casos en los que ha participado CA -que forma parte de SCL (Strategic Communication Laboratories)-, en los que se refiere a las actuaciones en las elecciones de Nigeria (África). En los apartados cuarto y quinto se analizan las características de la oferta laboral que recibió la autora después de acudir al Foro de Davos y tratar con potenciales clientes. El contenido de la obra pone de relieve que la empresa para la que trabajaba Kaiser estaba constantemente recopilando y analizando los asuntos que realmente preocupaban a las personas en cada momento. En definitiva, se buscaba disponer de lo que se podría denominar una suerte de identidad digital de un conjunto muy amplio de personas, para incidir sobre sus decisiones.

Los siguientes capítulos (cinco a diez y doce) se enfocan en las particularidades que rodearon la campaña presidencial de Donald Trump. El aparente candidato inesperado que no buscaba la victoria frente a Clinton, logró ganar gracias al trabajo de Kaiser y sus compañeros. Contra todo pronóstico, se impuso lo que parecía una quimera imposible de alcanzar. Este no fue el único acontecimiento cuyo desenlace estuvo condicionado por CA, ya que también prestó sus servicios para el referéndum en el que se decidiría la salida del Reino Unido de la Unión Europea (en la historia reciente ya se habían celebrado otros dos referéndums que datan de 1975 y 2011). El Brexit es objeto de examen en el capítulo once. Los votantes a favor de la salida del espacio comunitario se impusieron por algo más del $51 \%$.

Tras el excelente trabajo realizado por CA en las elecciones norteamericanas, la obra se refiere a la importante consolidación y proyección internacional que protagoniza la consultora CA. A su vez, el capítulo catorce alude a cuestiones relativamente heterogéneas como la posible actuación de Rusia en las elecciones norteamericanas o las acciones del controvertido Julian Assange -portavoz de WikiLeaks-. Finalmente, la autora aborda su interés por la cadena de bloques, siendo que en aquel momento esta tecnología todavía no estaba tan desarrollada ni era tan reconocida como en la actualidad. El capítulo siguiente menciona las actuaciones que Kaiser y su empresa llevaron a cabo en las elecciones mexicanas. Abundando en este tema, CA también tuvo una importante repercusión en India, Kenia, Nigeria, República Checa y Argentina.

Todos los capítulos posteriores se refieren a las reacciones que se suscitaron, a nivel mundial, tras conocerse las deleznables prácticas de la consultora. Los ciudadanos debían conocer que la democracia está en serio peligro, pero también que las decisiones que en su momento creyeron tomar libremente realmente no lo eran, sino que fueron resultado de la manipulación. 
En su obra, Brittany Kaiser hace un recorrido exhaustivo por diversas reuniones a las que asistió y los desconocidos métodos vulneradores de la privacidad que se utilizaron en numerosos asuntos claves de nuestro tiempo. En definitiva, podemos mostrar sin ambages la escala masiva que ha logrado el espionaje, la injerencia sin fundamento e ilícita en la vida privada de las personas y el fin del derecho a la privacidad: la utopía de un panóptico universal. La ética, la transparencia y la libertad deben estar presentes en la realidad cotidiana. Especialmente sugerentes resultan las apreciaciones formuladas por Kaiser para concienciar al lector acerca de la necesidad de proteger nuestros datos y la democracia. La autora ha creado una fundación que denominó Own Your Data (sé dueño de tus datos).

David López Jiménez

Revisado por José Morales

\section{Foucault, Michel (2018), O enigma da revolta: entrevistas inéditas sobre a Revolução Iraniana. São Paulo: n-1 edições, 144 pp. Traduzido por Lorena Balbino}

Quarenta anos após a Revolução Iraniana (1978-1979), revisitar o processo a partir das percepções sobre a potencialidade da insurgência através da perspectiva de um crítico como Michel Foucault significa não reduzir os levantes a um movimento de retorno à religião para formação de uma teocracia. No anseio do povo iraniano que se insurge, é possível verificar um desejo de mudança que assume o risco do confronto, como sugere o filósofo. As múltiplas entrevistas e palestras realizadas por Foucault são uma das marcas de seu percurso e resultam em publicações e traduções constantes, como os diversos tomos de Dits et écrits. Ao desvelar as fissuras daquilo que parece evidente, Foucault assumiu a posição de intelectual específico por ele mesmo reivindicada. Exemplificativamente, esse tipo de desvelamento verifica-se em suas percepções sobre o Irã presentes nestas entrevistas por chamarem atenção às práticas de insurreição e à incomensurabilidade de qualquer explicação óbvia. Se, em suas análises sobre o "poder" desmistificou esquemas e o pensou enquanto relações, as novas revoltas populares são pesquisas relevantes sobre desmistificação dos arranjos revolucionários do Ocidente para se pensar outras formas de resistência.

A publicação de $O$ enigma da revolta reúne postumamente duas entrevistas inéditas concedidas por Foucault em 1979 sobre as manifestações desencadeadoras da Revolução Iraniana, para além de ter uma apresentação de Lorena Balbino, um artigo de Farès Sassine ("Sobre entrevistar Michel Foucault”), e um posfácio de Christian Laval ("Foucault e a experiência utópica"). As entrevistas visam esclarecer as repercussões midiáticas das análises do filósofo sobre o processo revolucionário - que este teve oportunidade de acompanhar em duas visitas realizadas ao país em 1978, tendo produzido inclusive uma "Reportagem de ideias" para o periódico Corriere della Sera - e também são importantes para a compreensão do desenvolvimento de novas formas de insurreições populares no século $\mathrm{xx}$, bem como para recolocar os limites e os desafios das análises produzidas por intelectuais.

A primeira entrevista foi concedida à revista semanal Le Nouvel Observateur 
em junho de 1979, tendo sido apenas divulgada em 2018 neste livro. A questão central foi a tentativa de esclarecimento sobre a expressão "espiritualidade política", motor da insurreição iraniana, ideia veiculada por Foucault em uma reportagem anterior do mesmo jornal sobre o Irã. Buscando desvincular a expressão de um conceito estritamente religioso, o filósofo explica que tentava compreender a força que significava concomitantemente uma intensa sublevação contra um regime demasiadamente forte e a assunção de sacrifícios pelos revoltosos. Assim, define a espiritualidade como a prática do homem de se insurgir em relação à própria posição de sujeito que lhe foi fixada pelo poder, que se traduziria na vontade de "tornar-se outro do que se é". O uso da noção de espiritualidade deveria ser compreendido de acordo com suas influências teóricas e, desta forma, retoma a concepção de experiência de Bataille, definida como o risco que o sujeito assume ao tornar-se outro. Foucault inovou ao tentar demonstrar que o processo revolucionário iraniano não se centrava na oposição entre a crítica a uma modernização acelerada e a vontade de regressão a uma vida antiga, mas antes na reivindicação por outra forma de vida. Nesse sentido, demonstra bem que a religião islâmica concretizaria, através de um movimento político, a vontade de espiritualidade de ser outro para além do que se é. Foucault destaca ainda a presença da espiritualidade em grandes revoltas - exemplificadas nas grandes mudanças ocorridas no fim da Idade Média na Europa -, motivadas por inúmeros levantes, desmistificando qualquer cumplicidade com o islamismo.

A partir da leitura da obra surgem indagações acerca das razões das insurreições aparecerem sob uma vontade de espiritualidade em estado nu que podem adquirir uma roupagem religiosa para além do caso iraniano, rompendo-se com o modelo esquemático de revolução pensado no Ocidente. Por outro lado, o convite à necessidade da prática permanente de sublevação - na qual há recusa do atual estatuto de sujeito feito pelo pensador - revelaria a concretude da espiritualidade política e a reatualização de ações insubmissas desvinculadas de projetos religiosos.

$\mathrm{Na}$ segunda entrevista concedida a Farès Sassine em agosto de 1979 e divulgada em árabe em 2013, Foucault informa que o interesse pelo Irã adveio da leitura do livro O princípio esperança, de Ernest Bloch, e as concomitantes notícias veiculadas sobre os levantes iranianos. $\mathrm{Na}$ obra em tela, coloca-se na Idade Média europeia o surgimento de uma percepção coletiva da história orientada pela possibilidade de alteração do mundo; percepção de origem religiosa e, ao mesmo tempo, conteúdo que permitiria desenvolver a ideia de revolução. As manifestações no Irã, por sua vez, demonstrariam o posicionamento de um povo contra o regime sem os moldes revolucionários ocidentais, vinculado à importância do fenômeno religioso, o que parecia materializar o indicado por Ernest Bloch.

Farès Sassine, no texto que antecede a transcrição da entrevista, esclarece o contexto e a forma de desenvolvimento do diálogo com o filósofo sobre as análises da Revolução Iraniana. O jornalista traz importantes informações quanto à proximidade de Foucault com eruditos árabes, às polêmicas relativas às suas declarações sobre a insurgência iraniana, além de sublinhar as conclusões ainda titubeantes do intelectual em relação ao movimento. Três noções compreendidas como sendo de preocupação da parte de Foucault foram trazidas para esclarecimento nessa entrevista: "vontade geral", "governo islâmico" e "espiritualidade política". 
A impressão do filósofo quanto à "vontade geral" estaria relacionada à materialização de uma agregação coletiva iraniana contra o regime, sem qualquer guia, que não se restringiria à mera contestação. Em relação à equivocidade do termo "governo islâmico”, o filósofo demonstra que o seu consenso estaria na tentativa de se encontrar formas de coexistência que não reproduzissem o modelo ocidental. À noção de “espiritualidade política”, sua explicação remonta à analogia do que ocorrera na Europa com o calvinismo, esclarecendo que nunca almejou no contexto revolucionário iraniano detectar um tipo de retorno ao sagrado - a possibilidade efetiva do islamismo propiciar uma nova forma política seria da responsabilidade dos muçulmanos.

É relevante a explicação trazida por Foucault sobre a incomensurabilidade dos motivos que levam alguém a combater um sistema que o oprime, preferindo o risco da morte à submissão. Por isso, as razões dessa revolta seriam enigmáticas. $\mathrm{O}$ enigma da revolta - ou seja, a dimensão do inexplicável no ato de insurgência - impede qualquer explicação fácil sobre as causas e motivações do movimento de sublevação. Ademais, o argumento de Foucault sobre o papel dos intelectuais - de desmantelar o que pareceria óbvio e evidente na realidade a partir do trabalho que realizam, demonstrando as fragilidades e possibilidades de revolta - indica sua função ativa e crítica. Ele sugere-nos a necessidade de uma estratégia de insurreição consistente no inconformismo ao intolerável e na materialização de mudanças, que não é necessariamente massiva e tantas vezes ocorre no âmbito das relações interpessoais em suas diversas dimensões. Assim, aponta que não pode haver sociedades sem insurreições. Por último, acrescenta-se a importância da experiência utópica no pensamento foucaultiano trazida no posfácio de Christian Laval. Uma concepção de utopia que não é idealizada, segundo a leitura de Laval de Foucault, porém movimento que altera a relação consigo próprio e com o mundo a partir do resultado da própria transformação de si. Transformação potente que desloca os sujeitos, particular ou coletivamente, no exercício da prática da liberdade. Ainda é preciso ler que a utopia concretizada na mudança expõe o risco da morte. A espiritualidade do povo iraniano, assim identificada por Foucault, pode ser um exemplo de vislumbre da experiência utópica.

Grazielle da Silveira Pereira

Revisto por Alina Timóteo e Ana Sofia Veloso 


\section{David López Jiménez}

EAE Business School

Príncipe de Vergara, 156, C.P. 28002 Madrid, España

Contacto: dlopez@eae.es

ORCID: https://orcid.org/0000-0002-7013-9556

\section{Grazielle da Silveira Pereira}

Doutoranda em Teoria do Estado e Direito Constitucional, Pontifícia Universidade Católica do Rio de Janeiro

Rua Marquês de São Vicente, 225, CEP 22.451-900 Gávea, Rio de Janeiro, Brasil

Contacto: grazis.pereira@gmail.com

ORCID: https://orcid.org/0000-0002-3145-9856 